\title{
Misuse of Inhaled Bronchodilator Agents
}

\author{
K. B. SAUNDERS,* M.B., M.R.C.P.
}

Brit. med. F., 1965, 1, 1037-1038

In the course of doing simple lung-function tests on patients with chronic bronchitis, asthma, or emphysema it became clear that many of those using bronchodilator aerosols were not using them correctly. Since it seemed possible that such patients might not be gaining maximum benefit, and since the recently developed pressurized aerosols are expensive, it was thought reasonable to examine in more detail the use and effect of inhaled bronchodilators in out-patients routinely attending a chest department.

\section{Procedure}

Forty-six subjects were studied. They were a consecutive series of patients who had used sprays for periods varying from twelve years to one month, seen personally in the course of routine out-patient sessions.

Each answered a standard questionary, the main purpose of. which was to elicit the total amount of bronchodilator used by the patients and its subjective effect. Dyspnoea was graded by the same questions as those used in the M.R.C. Short Questionnaire on Respiratory Symptoms (1960). Further questions were asked to define those people who used their sprays only when they had acute attacks of breathlessness. Such patients were excluded from the survey as it was felt that lack of response to bronchodilators under test conditions, when there was no acute dyspnoea, was not necessarily significant. The oral bronchodilator regime, if any, was recorded.

Baseline measurements of peak expiratory flow rate (P.E.F.R.), five readings in all, were then taken, and the mean of the highest three readings was recorded. These measurements were made with a Wright peak flow meter (Wright and McKerrow, 1959). Measurements of the forced expiratory volume in one second (F.E.V..$_{1}$ ) and forced vital capacity (F.V.C.) were made, using the McDermott dry spirometer (Collins, McDermott, and McDermott, 1965). Three readings were taken and the mean of the highest two was recorded.

The patient then used his own spray or aerosol as he normally did, and after five minutes further measurements of P.E.F.R., F.E.V..$_{1}$, and F.V.C. were made. The type of spray and the way in which it was used were recorded.

Finally the patient breathed $1 \%$ isoprenaline from an aerosol generator devised by L. Dautrebande (the D30) and shown by him to be highly effective (Dautrebande and Lovejoy, 1961). A third set of readings was taken, and the patient was then asked if he had ever been shown how to use the spray, and if so by whom, or if he had ever read any instructions.

The purpose of this procedure was to detect whether the patient achieved maximal bronchodilatation by normal use of his own spray. It assumes that five minutes after the first inhalation the response has reached a peak, and that further response after a second and possibly more efficient application of isoprenaline represents a further degree of bronchodilatation.

In procedures comparing measurements of P.E.F.R., F.E.V., and F.V.C. from two sets of patients-for example, in controlled

* Registrar, Department of Thoracic Medicine (now Lecturer, Department of Medicine), St. Thomas's Hospital, London. trials-it is usual to take the mean of the last two (or three) readings in each patient. In this series three separate sets of readings were taken from each patient on the same occasion and compared against each other; the mean of the highest two (or three) readings was taken as it was found that it gave more consistent values, and it was felt to be more representative of the subject's maximum achievement at the time of measurement.

The correct use of a pressurized aerosol container-for example, Medihaler-involves a full expiration, the release of a dose of inhalant timed with a full inhalation, and breath-holding for as long as possible afterwards. The procedure may be repeated. It was recorded as correct or incorrect.

The correct use of a rubber-bulb nebulizer is more difficult to assess. Probably the best way is to breathe deeply and slowly without breath-holding, timing pressure with each inhalation. However, an attempt was made to assess efficiency and record it as correct or incorrect.

A $20 \%$ increase in P.E.F.R., F.E.V. ${ }_{1}$, or F.V.C. was arbitrarily selected as indicating a positive response to bronchodilators.

On this basis the patients could be divided into four groups showing: (1) no response to their own spray or to the second efficient application from the D30 generator ; (2) no response to their own spray, but a positive response to the second ; (3) a response to the first spray, but no further response to the second ; (4) a response to the first spray, with a further response of $>20 \%$ to the second.

Those patients who achieved no response-that is, $<20 \%$ over baseline levels after the first spray, and then showed a response of $>20 \%$ over baseline levels after the second spray, but in whom the difference between these two values was less than $20 \%$, were included in group 3 . For example, a subject might achieve a P.E.F.R. of 200 , increased to 235 after using his own spray and to 245 after using the D30 aerosol generator. $\mathrm{He}$ is included in group 3 rather than group 2, since the latter implies that his own spray was not effective but that the D30 was ; this assumption would clearly be unjustified on the given figures.

\section{Results}

Efficiency of Inhaled Bronchodilators as Normally Used.The response of the 46 patients to an inhaled bronchodilator is shown in Table I. Thirteen (group 1) showed no significant

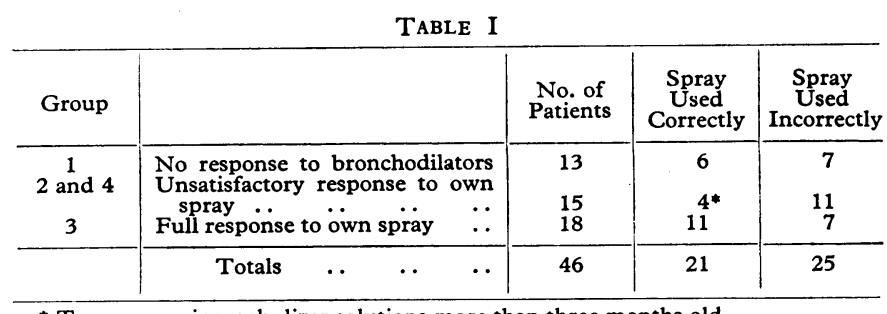

* Two were using nebulizer solutions more than three months old.

response either to their own spray or to the D30 aerosol. None of these had had oral bronchodilator drugs on the day of measurement. Three showed no response at all to their own spray but a positive response to the standard (group 2). Only one of these was using her spray correctly, and she was using a proprietary nebulizer, with a solution which she had had for 
six months. Twelve patients (group 4) showed a positive response to their own spray, with a further significant response to the standard aerosol, and are therefore assumed not to be obtaining the maximum benefit from their normal therapy. Of these, nine were using their spray incorrectly ; three were using it correctly, but again one of these was using a proprietary nebulizer and solution which he had had for five months. The remaining 18 patients (group 3) could be shown to respond to their own spray with no further response to the standard. Eleven of these were using their spray correctly. Excluding all those subjects shown not to respond significantly to bronchodilators, a comparison has been made between those who used pressurized aerosols and those who used rubber-bulb nebulizers (Table II). Of the 11 patients using a pressurized aerosol correctly, only two did not gain maximum response. Of the 14 using such an aerosol incorrectly, no fewer than 11 failed to gain maximum response.

TABLE II

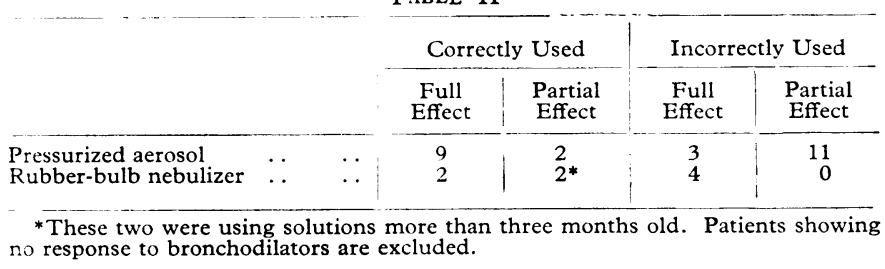

Age of Nebulizer Solutions.-Of the 12 patients using nebulizers, four were refilling them with solutions in their possession for more than three months; two of these had gained only partial benefit, although they used them correctly.

Original Prescriber.-The original prescription for the spray was given by the general practitioner in 16 cases, by this hospital in 27 , and by other hospitals in three.

Previous Instruction. - Thirty-three patients had previously been instructed in the correct use of their spray. Nine had been given written instructions. Only four had received neither form of direction.

\section{Discussion}

Chronic bronchitis is the second most important cause of morbidity in this country. Many bronchitics require bronchodilator therapy, given either by inhalation or orally. Inhalants are often prescribed alone, or in addition to oral bronchodilators, because they act faster and are at first sight easy to use. Pressurized containers are the most convenient and deliver a measured dose. It is clear that correct use of such an apparatus is essential ; but in this study it was not often attained.

In this clinic a reasonable attempt had been made to instruct each patient in the use of his spray on one occasion, a routine probably representative of that used in most busy out-patient departments. This survey shows that one initial period of instruction is inadequate. Centres which customarily take more care in instruction would expect to produce more effective therapy.

Of the eight subjects using rubber-bulb nebulizers, four used them incorrectly, but all used them for over one minute at each application. Only two failed to gain maximum bronchodilatation; both of these were using solutions five or more months old. A solution of isoprenaline 1\% B.P.C., in the usual brown glass bottle, was placed on a laboratory shelf not in direct sunlight. It became discoloured in 10 days.

\section{Summary}

A detailed inquiry was made into the use and effect of bronchodilators in 46 patients routinely attending a chest department.

Of these, 13 showed no response to bronchodilators under criteria defined above.

Eighteen gained full benefit from their spray as normally used.

The remaining 15 , though able to respond to bronchodilators, were gaining either a partial response or none at all. Eleven of these were using their spray incorrectly, and two were using solutions five or more months old.

I wish to thank Dr. D. S. Cadman 'for permission to study his patients, Dr. D. G. Wraith for the loan of the D30 aerosol generator, and Dr. W. W. Holland for his help and advice throughout.

\section{REFERENCES}

Collins, M. M., McDermott, M., and McDermott, T. J. (1965). f. Physiol. (Lond.). In press.

Dautrebande, L., and Lovejoy, F. W. (1961). Arch. int. Pharmacodyn., 131, 230 .

Wright, B. M., and McKerrow, C. B. (1959). Brii. med. F., 2, 1041.

\title{
A Eunuch Takes the Gout
}

\author{
A. J. S. MCFADZEAN,* O.B.E., M.D., F.R.C.P., F.A.C.P
}

Brit. med.. F., 1965, 1, 1038-1039

Eunuchs do not take the gout, nor become bald.Aphorism of Hippocrates.

Galen, in his commentary on the above aphorism, claims that it did not hold for the eunuchs of Imperial Rome. In an admirable presentation of the long and memorable history of gout Copeman (1964) paraphrases the commentary thus ". . . whilst agreeing that this [the aphorism] was basically true, [Galen] said that in his time, however, such was their indolence and viciousness that they [eunuchs] occasionally did so." On the other hand, the paraphrase by Adams (1849) of the same commentary reads, "while it was true in Hippocrates'

* University Department of Medicine, Queen Mary Hospital, Hong Kong. time that eunuchs did not take the gout in his [Galen's] time they were exposed to the disease because of their indolence and effeminacy." In each of two versions of the commentary available to me there are two sentences which, if divorced from their context, clearly convey that eunuchs suffered from the gout. "Ob hanc igitur causam etiam eunuchi podagra corripiuntur, quamuis nullum habeat usum venereorum. Talis enim est eorum desidia, ingluuies, ebrietas, ut etiam sine venereis podagra corripi possint" (1550). “ $\mathrm{Ob}$ has igitur causas eunuchi etiam podagrae doloribus cruciantur, etiamsi quam maxime sibi a venere temperent. Tanta enim eorum est desidia, tam inexplebilis edacitas, tanta crapula, ut etiam sine coitu, podagra corripi possint" (1633). However, the paraphrase by Adams (1849), provided he is allowed the delicacy of 